\title{
Levels and distribution of polychlorinated biphenyls in the atmosphere close to Chinese Great Wall Station, Antarctica: Results from XAD-resin passive air sampling
}

\author{
LI YingMing ${ }^{1}$, GENG DaWei ${ }^{2,1}$, HU YongBiao ${ }^{3,1}$, WANG Pu $^{1}$, ZHANG QingHua $^{1 *} \&$ \\ JIANG GuiBin ${ }^{1}$ \\ ${ }^{1}$ State Key Laboratory of Environmental Chemistry and Ecotoxicology, Research Center for Eco-Environmental Sciences, Chinese Academy of \\ Sciences, Beijing 100085, China; \\ ${ }^{2}$ School of Energy Resources, China University of Geosciences (Beijing), Beijing 100083, China; \\ ${ }^{3}$ College of Resources and Environment, Huazhong Agricultural University, Wuhan 430070, China
}

Received September 13, 2011; accepted January 17, 2012; published online March 12, 2012

\begin{abstract}
Antarctica is an important research region for assessing persistence and long-range atmospheric transport (LRAT) of persistent organic pollutants (POPs). In this study, XAD-resin passive air sampling was conducted near the Chinese Great Wall Station, Antarctica, during a one-year sampling period in 2009-2010. The air concentrations of polychlorinated biphenyls (PCBs) were at a very low level, with total PCBs in the range of 26.74-45.08 $\mathrm{pg} \mathrm{m}^{-3}$. PCB profiles were dominated by tetra-PCBs, tri-PCBs and di-PCBs, indicating LRAT was responsible for the pollutants in the Antarctic atmosphere. The sampling site near the Chinese Great Wall Station did not show higher PCB levels than the other sites, suggesting that PCB sources associated with the Great Wall Station were negligible. PCB-11 is a non-Aroclor congener, which has specific sources compared to other Aroclor PCB congeners. PCB-11 was observed in all air samples, with an average concentration of $1.22 \mathrm{pg} \mathrm{m}^{-3}$. To our knowledge, this study is the first investigation of PCB levels and distribution in the atmosphere around the Chinese Great Wall Station, Antarctica.
\end{abstract}

Antarctica, atmosphere, XAD-resin passive air sampling, PCBs, PCB-11

Citation: $\quad$ Li Y M, Geng D W, Hu Y B, et al. Levels and distribution of polychlorinated biphenyls in the atmosphere close to Chinese Great Wall Station, Antarctica: Results from XAD-resin passive air sampling. Chin Sci Bull, 2012, 57: 1499-1503, doi: 10.1007/s11434-012-5048-8

Antarctica is a pristine area with few human activities. It is an important research region for assessing persistence and long-range atmospheric transport (LRAT) of persistent organic pollutants (POPs) [1]. Atmosphere plays a key role for the transfer of POPs from source regions to remote areas, including the Antarctic region. The presence of POPs has been found in various Antarctic compartments in a few studies, including the air [2-4], soil [5], plants [6] and animals [7-10]. One of the most observed POPs in the Antarctic environment is polychlorinated biphenyl (PCB), which has been produced and used historically in electrical transformers and capacitors. Although the production and appli-

*Corresponding author (email: qhzhang@ @rcees.ac.cn) cation of PCBs has been banned since the 1970s in most countries, PCBs have aroused continuing attention due to persistence in the environment, high toxicity and bio-accumulation properties in food webs. Industrial thermal processes can also produce and release PCBs into the ambient air as a byproduct.

Because Antarctica is far from sources, LRAT is considered as the main factor bringing PCBs to the Antarctic environment [3]. On the other hand, local sources from Antarctic research stations should also be considered in recent years; increasing scientific research activities and tourism could put escalating pressures on the Antarctic environment [2]. Most studies for air monitoring of POPs in Antarctica used high-volume air samplers. However, the need for 
electricity largely limited their use in truly remote areas of Antarctica. Since the 2000s, various passive air samplers, such as the most commonly used XAD-resin [11] and polyurethane foam (PUF) disk passive air samplers [12,13], have been developed and successfully used in the air monitoring of POPs in different regions [14-17]. For passive air monitoring in the Antarctic atmosphere, only Choi et al. [3] applied XAD passive air samplers, near the Korean Antarctic Research Station.

Although sparse studies reported the presence of PCBs in Antarctic air, including those at Signy Island [18], the Brazilian Antarctic Research Station [19], Terra Nova Bay [2], and the Korean Antarctic Research Station [3], PCB data for Antarctic air was still limited. Since 2009, we carried out comprehensive air monitoring of POPs in the vicinity of the Chinese Great Wall Station in Antarctica using high-volume air samplers, PUFs and XAD-resin passive air samplers. In this study, we report the air monitoring data from XADresin passive air samplers in a one-year sampling period from austral summer 2009 to austral summer 2010. The air concentrations, distributions, as well as potential sources of PCBs near the Chinese Great Wall Station are discussed. To our knowledge, this study is the first investigation of PCB concentrations in the atmosphere around the Chinese Great Wall Station, Antarctica.

\section{Method and materials}

\subsection{Sample collection}

Air samples were collected at four sampling sites near the Chinese Great Wall Station, Antarctica (S62 12'59", W58 $57^{\prime} 52^{\prime \prime}$ ), using XAD-resin passive air samplers [11]. The Great Wall Station was built in 1985 and is located on King George Island of the South Shetland Islands in West Antarctica. Sampling site SS-1 was the site nearest the Great Wall Station in this study. Site SS-2 was along the south seacoast, and site SS-3 was close to the west seacoast. Site SS-4 was located on Ardley Island, also called Penguin Island. The map of the sampling sites is shown in Figure 1.

Passive air samples were collected from the austral summer of 2009 to the austral summer of 2010, during the XXVI and XXVII Chinese Scientific Research Expedition to Antarctica. To minimize possible interferences, the XAD resin was pre-cleaned with ethanol, acetone and hexane, respectively, before use. After one year of deployment, the $\mathrm{XAD}$ resin was sealed in stainless steel tubes. After transport to the laboratory, samples were stored at $-20^{\circ} \mathrm{C}$ until analysis. The annual average temperature and wind speed in the sampling area were $-2.8^{\circ} \mathrm{C}$ and $7.2 \mathrm{~m} \mathrm{~s}^{-1}$, respectively.

\subsection{Sample analysis}

PCB analysis was performed according to U.S. EPA method 1668A, with minor revisions. Prior to sample extraction in

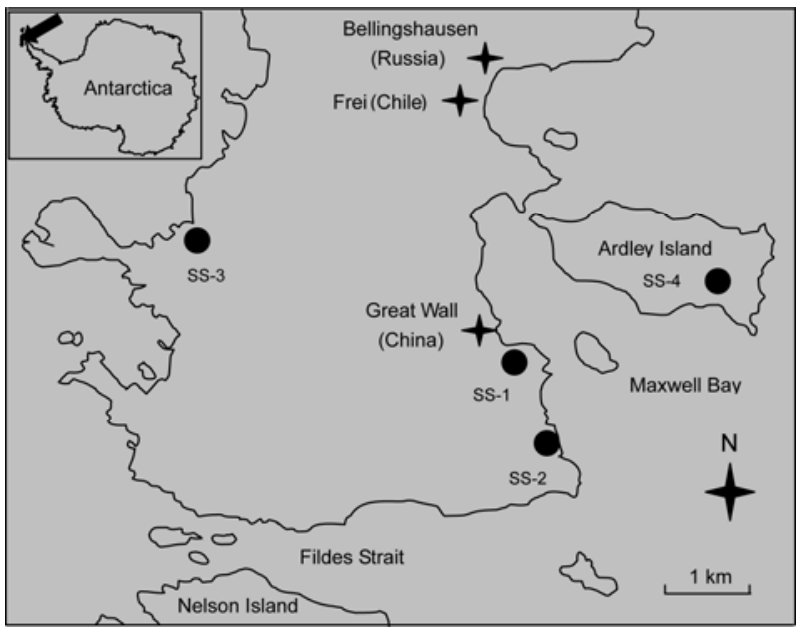

Figure 1 Map of sampling sites.

an accelerated solvent extraction (ASE) apparatus (Dionex ASE 300), the air samples were spiked with $1 \mathrm{ng}$ of isotopelabeled surrogate standards of PCBs $\left(68 \mathrm{~A}-\mathrm{LCS},{ }^{13} \mathrm{C}_{12}\right.$-labeled PCB congeners). After evaporation, the extract was subjected to cleanup in multilayer silica ( $1 \mathrm{~g}$ neutral silica, $4 \mathrm{~g}$ basic silica, $1 \mathrm{~g}$ neutral silica, $8 \mathrm{~g}$ acid silica, $2 \mathrm{~g}$ neutral silica, $4 \mathrm{~g}$ anhydrous sodium sulfate) and carbon columns. The final extract was concentrated to $\sim 20 \mu \mathrm{L}$ and spiked with $1 \mathrm{ng}$ of ${ }^{13} \mathrm{C}_{12}$-labeled injection standards $\left({ }^{13} \mathrm{C}_{12}\right.$-PCB-9, 52, 101, 138 and ${ }^{13} \mathrm{C}_{12}$-PCB-194).

The final extract was injected into an Agilent 6890 gas chromatograph coupled with a Micromass AutoSpec Ultima high-resolution mass spectrometer (HRMS), which was operated in selected ion mode with a mass resolution of 10000. A GC column of $60 \mathrm{~m}$ DB-5 MS was used for GC separations. In this study, PCB-77, PCB-81, PCB-105, PCB-114, PCB-118, PCB-123, PCB-126, PCB-156, PCB-157, PCB-167, PCB-169, PCB-189, PCB-28, PCB-52, PCB-101, PCB-138, PCB-153, PCB-180, PCB-11, di-PCBs, tri-PCBs, tetra-PCBs, penta-PCBs, hexa-PCBs, hepta-PCBs, octa-PCBs, nona-PCBs and deca-PCBs were quantified. Detailed instrument methods can be found elsewhere [20,21].

One field blank and one laboratory blank sample were analyzed for the purpose of quality control. The blank values were very low, $<20 \%$ of the air samples. The sample recoveries of ${ }^{13} \mathrm{C}_{12}$-labeled surrogate standards were in the range of $35 \%-67 \%$, which meets the recovery limit of EPA method 1668A. The limit of detections (LOD), defined as three times the signal/noise ratio, were in the range of 0.0002-0.002 $\mathrm{pg} \mathrm{m}^{-3}$ for PCB congeners.

\section{Results and discussion}

\subsection{PCB concentrations in the air}

Detailed PCB concentrations in the air are summarized in Table 1. Because the sampling rate of XAD-resin passive 
air samplers was not strongly dependent on wind speeds and POPs can remain in the linear uptake stage after a one-year exposure [11], a sampling rate of $3.5 \mathrm{~m}^{3} \mathrm{~d}^{-1}$ was used for the calculation of air concentrations in this study. In the following discussion, the total PCBs represents the sum concentrations of di-PCBs, tri-PCBs, tetra-PCBs, pentaPCBs, hexa-PCBs, hepta-PCBs, octa-PCBs, nona-PCBs and deca-PCBs. The $\Sigma_{7} \mathrm{PCBs}$ represents the air concentrations of indicator PCBs (PCB-28, PCB-52, PCB-101, PCB-118, PCB-138, PCB-152, and PCB-180). The PCB concentrations

Table 1 PCB concentrations in Antarctic air $\left(\mathrm{pg} \mathrm{m}^{-3}\right)^{\mathrm{a})}$

\begin{tabular}{|c|c|c|c|c|}
\hline & SS-1 & SS-2 & SS-3 & SS-4 \\
\hline PCB-77 & 0.006 & 0.010 & 0.006 & 0.008 \\
\hline PCB-81 & n.d. & n.d. & n.d. & 0.004 \\
\hline PCB-105 & 0.016 & 0.012 & 0.012 & 0.016 \\
\hline PCB-114 & 0.002 & 0.002 & 0.002 & 0.004 \\
\hline PCB-118 & 0.034 & 0.026 & 0.024 & 0.036 \\
\hline PCB-123 & 0.002 & 0.002 & 0.002 & n.d. \\
\hline PCB-126 & n.d. & n.d. & n.d. & n.d. \\
\hline PCB-156 & 0.004 & 0.002 & 0.002 & 0.004 \\
\hline PCB-157 & n.d. & n.d. & n.d. & n.d. \\
\hline PCB-167 & 0.002 & 0.002 & n.d. & n.d. \\
\hline PCB-169 & n.d. & n.d. & n.d. & n.d. \\
\hline PCB-189 & n.d. & n.d. & n.d. & n.d. \\
\hline PCB-28 & 0.57 & 1.08 & 1.10 & 0.28 \\
\hline PCB-52 & 0.068 & 0.056 & 0.13 & 0.21 \\
\hline PCB-101 & 0.086 & 0.14 & 0.32 & 0.084 \\
\hline PCB-138 & 0.032 & 0.048 & 0.030 & 0.036 \\
\hline PCB-153 & 0.028 & 0.040 & 0.032 & 0.040 \\
\hline PCB-180 & 0.010 & 0.008 & 0.010 & 0.012 \\
\hline PCB-11 & 0.96 & 1.59 & 1.35 & 0.97 \\
\hline Di-PCBs & 4.91 & 7.88 & 6.46 & 5.31 \\
\hline Tri-PCBs & 8.35 & 18.79 & 11.48 & 4.71 \\
\hline Tetra-PCBs & 12.72 & 9.95 & 25.75 & 17.67 \\
\hline Penta-PCBs & 0.65 & 0.92 & 1.28 & 0.64 \\
\hline Hexa-PCBs & 0.11 & 0.17 & 0.10 & 0.13 \\
\hline Hepta-PCBs & 0.022 & 0.020 & 0.020 & 0.032 \\
\hline Octa-PCBs & 0.008 & 0.008 & 0.006 & 0.012 \\
\hline Nona-PCBs & 0.002 & 0.004 & 0.002 & 0.004 \\
\hline Deca-PCBs & 0.006 & 0.008 & 0.010 & 0.016 \\
\hline$\Sigma_{7} \mathrm{PCBs}$ & 0.83 & 1.40 & 1.64 & 0.70 \\
\hline$\Sigma \mathrm{dl}-\mathrm{PCBs}$ & 0.066 & 0.056 & 0.048 & 0.072 \\
\hline Total PCBs & 26.74 & 37.76 & 45.08 & 37.77 \\
\hline WHO-TEQ PCBs & $9 \mathrm{E}-6$ & $7 \mathrm{E}-6$ & $6 \mathrm{E}-6$ & $1 \mathrm{E}-5$ \\
\hline
\end{tabular}

a) n.d.: not detectable; $\Sigma_{7} \mathrm{PCBs}$ represent the air concentrations of PCB-28, PCB-52, PCB-101, PCB-118, PCB-138, PCB-153 and PCB-180. in the atmosphere were at a very low level, with total PCBs in the range of 26.74-45.08 $\mathrm{pg} \mathrm{m}^{-3}$ (mean $36.84 \mathrm{pg} \mathrm{m}^{-3}$ ). The levels of $\Sigma_{7}$ PCBs varied from 0.70 to $1.64 \mathrm{pg} \mathrm{m}^{-3}$, with mean concentrations of $1.14 \mathrm{pg} \mathrm{m}^{-3}$. Sampling site SS-1, which was close to the Great Wall Station, did not show higher PCB concentrations than other sites. This result indicates that local PCB sources from the Chinese Great Wall Station are negligible. A few studies have suggested that local sources from Antarctic research stations may contribute PCBs to the ambient air $[3,19]$. For example, waste incineration and dumping were considered local PCB sources at the Brazilian Antarctic Research Station in the South Shetlands archipelago, Antarctica [19]. However, human activities from research stations during the entire year period could be omitted because most Antarctic research activities occurred only during the austral summer period. Subsequently, LRAT could be the key factor influencing the PCB levels in the vicinity of the Chinese Great Wall Station.

The PCB concentrations in this study were similar to the reported data in the vicinity of the Korean Antarctic Research Station ( $\sum_{205}$ PCBs: 11.07-30.75 $\mathrm{pg} \mathrm{m}^{-3}$ ) [3], which is approximately $20 \mathrm{~km}$ east of the Chinese Great Wall Station. We also compared air concentrations of indicator PCBs in this study with published data for other Antarctic sites. These were comparable to $\mathrm{PCB}$ concentrations in the air around Terra Nova Bay (PCB-28: 0.088-0.22 $\mathrm{pg} \mathrm{m}^{-3}$; PCB-52: $0.027-0.10 \mathrm{pg} \mathrm{m}^{-3}$ ) [2], but lower than those in the vicinity of the Brazilian Antarctic Research Station (PCB-52: 8.6 $\mathrm{pg} \mathrm{m}^{-3}$; PCB-101: $4.9 \mathrm{pg} \mathrm{m}^{-3}$; PCB-118: $4.7 \mathrm{pg} \mathrm{m}^{-3}$; PCB-138: $2.6 \mathrm{pg} \mathrm{m}^{-3}$; PCB-153: $4.0 \mathrm{pg} \mathrm{m}^{-3}$; PCB-180: 0.3 $\left.\mathrm{pg} \mathrm{m}^{-3}\right)$ [19] and those at Signy Island ( $\sum_{7}$ PCBs: $20.67 \mathrm{pg}$ $\left.\mathrm{m}^{-3}\right)$ [18].

The TEQs of dioxin-like PCBs were based on the 1998 World Health Organization Toxic Equivalent Factors. In the case of concentrations below the LOD, their values were taken as zero. The WHO-TEQ of PCBs in this study varied from 0.006 to $0.01 \mathrm{fg} \mathrm{m}^{-3}$, lower than the data from the Korean Antarctic Station (0.17 fg (WHO-TEQ) $\mathrm{m}^{-3}$ ) [3].

\subsection{Homolog profiles}

Relative distribution of PCB homologs is important because physical and chemical properties for each PCB homolog vary greatly (e.g., Henry's law constant, vapor pressure and octanol-air partition coefficient), and these can determine their atmospheric transport and environmental fate. For example, the light PCB congeners tend to volatilize and transport from source regions to remote areas through the atmosphere, whereas the heavy congeners tend to deposit and remain in the surface compartment. Figure 2 shows the relative contribution of $\mathrm{PCB}$ homologs. $\mathrm{PCB}$ profiles were dominated by tetra-PCBs (average contribution of $39.4 \%$ to the total PCBs), tri-PCBs (average contribution of 39.0\%) and di-PCBs (average contribution of 18.6\%). The heavier congeners, from hexa-PCBs to deca-PCBs, accounted for 


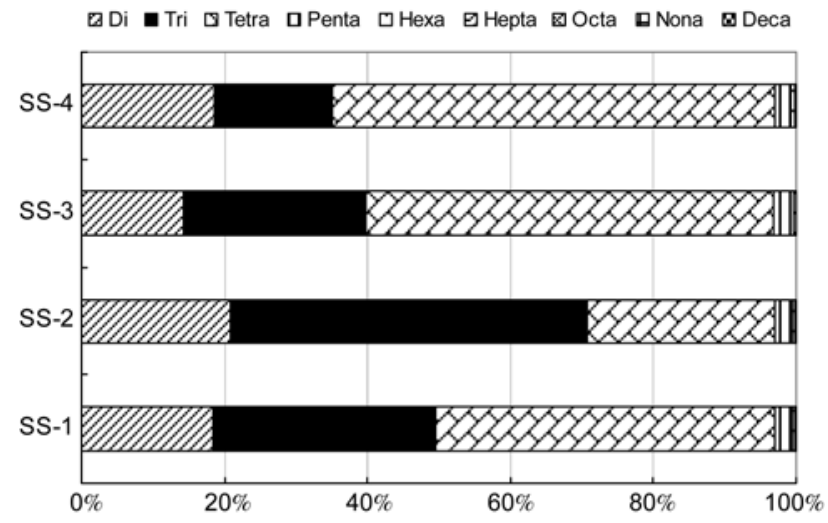

Figure 2 Relative contributions of PCB homologs.

less than $3 \%$ of the total PCBs. The abundance of volatile PCB homologs in this study confirms the assumption that PCB composition experiences a global fractionation, i.e. more volatile PCBs move toward higher latitudes globally. This result also indicates that LRAT is responsible for the occurrence of PCBs in the vicinity of the Chinese Great Wall Station. Similar results were reported at Signy Island [19], the Korean Antarctic Research Station [3], Terra Nova Bay [2] and the Brazilian Antarctic Research Station [19]. The homolog of tri-PCBs dominated the PCB profiles at site SS-2, which contradicts those for other sites. Several confounding factors could influence atmospheric PCB levels and homologs (e.g. the degradation process, air-sea exchange, air mass and anthropogenic activities). Sampling site SS-2 is located on a mountain slope along the seacoast, whereas the other sites are located in open fields. The mountain slope can block the wind or air mass from western sea directions and shield the samplers from sunlight, which could result in less degradation and be related to specific PCB homologs for the air sample at site SS-2.

\subsection{Occurrence of PCB-11}

PCB-11 (3,3'-dichlorobiphenyl) is a non-Aroclor congener. It cannot be found in commercial Aroclor and Clophen mixtures [22]. However, it is associated with paint and pigment manufacturing as a byproduct [23]. In recent years, PCB-11 has aroused great concern and has been found ubiquitously in the air around Chicago [23], the Great Lakes [24], Philadelphia [25], and even in Arctic and Antarctic air [3]. In this study, PCB-11 was observed in all air samples. Air concentrations of PCB-11 varied from $0.96 \mathrm{pg} \mathrm{m}^{-3}$ to $1.59 \mathrm{pg} \mathrm{m}^{-3}$, with a mean of $1.22 \mathrm{pg} \mathrm{m}^{-3}$. This result was lower than data from the Korean Antarctic Research Station (average $60 \mathrm{pg} \mathrm{m}^{-3}$ ) [3]. PCB-11 was the most abundant congener in this study, and showed even higher concentrations than indicator PCBs. The contribution of PCB-11 to the total $\mathrm{PCBs}$ varied from $2.73 \%$ to $3.68 \%$ in the air samples. However, the sources of PCB-11 in the Antarctic air are not very clear, and therefore require more intensive investigation [3].

\section{Conclusions}

In this study, we carried out XAD-resin passive air samplings in the vicinity of the Chinese Great Wall Station, Antarctica. PCBs can be detected in the air samples at a very low level, reflecting the pristine state of the Antarctic air. The PCB concentrations in this study were similar to or lower than the reported data for other Antarctic sites. The non-Aroclor congener PCB-11 was observed in all samples, reflecting its global distribution in the atmosphere. Results from this study also indicate that local PCB sources from the Chinese Great Wall Station are negligible, whereas LRAT could be the key factor influencing PCB levels in the Antarctic air over a long period.

This work was supported by the State Oceanic Administration, P.R. China (09/10GW08 and 10/11GW02), National Natural Science Foundation of China (20897011 and 20907059), and National Basic Research Program of China (2009CB421600). We also thank Chinese Arctic and Antarctic Administration for arrangements during the XXVI and XXVII Chinese Antarctic Expeditions.

1 Wit C A, Herzke D, Vorkamp K. Brominated flame retardants in the Arctic environment-trends and new candidates. Sci Total Environ, 2010, 408: 2885-2918

2 Gambaro A, Manodori L, Zangrando R, et al. Atmospheric PCB concentrations at Terra Nova Bay, Antarctica. Environ Sci Technol, 2005, 39: 9406-9411

3 Choi S D, Baek S Y, Chang Y S, et al. Passive air sampling of polychlorinated biphenyls and organochlorine pesticides at the Korean arctic and Antarctic Research Stations: Implications for long-range transport and local pollution. Environ Sci Technol, 2008, 42: 7125-7131

4 Baek S Y, Choi S D, Chang Y S. Three-year atmospheric monitoring of organochlorine pesticides and polychlorinated biphenyls in Polar Regions and the South Pacific. Environ Sci Technol, 2011, 45: 4475-4482

5 Negoita T G, Covaci A, Gheorghe A, et al. Distribution of polychlorinated biphenyls (PCBs) and organochlorine pesticides in soils from the East Antarctic coast. J Environ Monitor, 2003, 5: 281-286

6 Park H, Lee S H, Kim M, et al. Polychlorinated biphenyl congeners in soils and lichens from King George Island, South Shetland Islands, Antarctica. Antarct Sci, 2010, 22: 31-38

7 Corsolini S, Kannan K, Imagawa T, et al. Polychloronaphthalenes and other dioxin-like compounds in Arctic and Antarctic marine food webs. Environ Sci Technol, 2002, 36: 3490-3496

8 Aono S, Tanabe S, Fujise Y, et al. Persistent organochlorines in minke whale (Balaenoptera acutorostrata) and their prey species from the Antarctic and the North Pacific. Environ Pollut, 1997, 98: 81-89

9 Schiavone A, Corsolini S, Borghesi N, et al. Contamination profiles of selected PCB congeners, chlorinated pesticides, PCDD/Fs in Antarctic fur seal pups and penguin eggs. Chemosphere, 2009, 76: 264-269

10 Nash S M B, Poulsen A H, Kawaguchi S, et al. Persistent organohalogen contaminant burdens in Antarctic krill (Euphausia superba) from the eastern Antarctic sector: A baseline study. Sci Total Environ, 2008, 407: 304-314

11 Wania F, Shen L, Lei Y D, et al. Development and calibration of a resin based passive sampling system for monitoring persistent organic pollutants in the atmosphere. Environ Sci Technol, 2003, 37: 1352-1359 
12 Shoeib M, Harner T. Characterization and comparison of three passive air samplers for persistent organic pollutants. Environ Sci Technol, 2002, 36: 4142-4151

13 Harner T, Shoeib M, Diamond M, et al. Using passive air samplers to assess urban-rural trends for persistent organic pollutants. 1. Polychlorinated biphenyls and organochlorine pesticides. Environ Sci Technol, 2004, 38: 4474-4483

14 Jaward F M, Zhang G, Nam J J, et al. Passive air sampling of polychlorinated biphenyls, organochlorine compounds, and polybrominated diphenyl ethers across Asia. Environ Sci Technol, 2005, 39: 8638-8645

15 Jaward F M, Farrar N J, Harner T, et al. Passive air sampling of PCBs, PBDEs and Organochlorine Pesticides across Europe. Environ Sci Technol, 2004, 38: 34-41

16 Pozo K, Harner T, Wania F, et al. Toward a global network for persistent organic pollutants in air: Results from the GAPS study. Environ Sci Technol, 2006, 40: 4867-4873

17 Gouin T, Harner T, Blanchard P, et al. Passive and active air samplers as complementary methods for investigating persistent organic pollutants in the Great Lakes Basin. Environ Sci Technol, 2005, 39: 9115-9122

18 Kallenborn R, Oehme M, Wynn-Williams D D, et al. Ambient air levels and atmospheric long-range transport of persistent organochlo- rines to Signy Island, Antarctica. Sci Total Environ, 1998, 220: 167-180

19 Montone R C, Taniguchi S, Weber R R. PCBs in the atmosphere of King George Island, Antarctica. Sci Total Environ, 2003, 308: 167-173

20 Li Y M, Zhang Q H, Ji D S, et al. Levels and vertical distributions of PCBs, PBDEs, and OCPs in the Atmospheric Boundary Layer: Observation from the Beijing 325-m Meteorological Tower. Environ Sci Technol, 2009, 43: 1030-1035

21 Li Y M, Jiang G B, Wang Y W, et al. Concentrations, profiles and gas-particle partitioning of PCDD/Fs, PCBs and PBDEs in the ambient air of an E-waste dismantling area, Southeast China. Chin Sci Bull, 2008, 53: 521-528

22 Schulz D E, Petrick G, Duinker J C. Complete characterization of polychlorinated biphenyl congeners in commercial aroclor and clophen mixtures by multidimensional gas-chromatography electroncapture detection. Environ Sci Technol, 1989, 23: 852-859

23 Hu D F, Martinen A, Hornbuckle K C. Discovery of non-aroclor PCB (3,3'-dichlorobiphenyl) in Chicago Air. Environ Sci Technol, 2008, 42: 7873-7877

24 Basu I, Arnold K A, Venier M. Partial pressures of PCB-11 in air from Several Great Lakes Sites. Environ Sci Technol, 2009, 43: 6488-6492

25 Du S, Wall S J, Cacia D, et al. Passive air sampling for polychlorinated biphenyls in the Philadelphia Metropolitan Area. Environ Sci Technol, 2009, 43: 1287-1292

Open Access This article is distributed under the terms of the Creative Commons Attribution License which permits any use, distribution, and reproduction in any medium, provided the original author(s) and source are credited. 